\title{
Pengembangan Aplikasi Aok-Jek Menggunakan Kerangka Kerja COBIT 4.1 Untuk Meningkatkan Pelayanan Pelanggan
}

\author{
Agus Dendi Rachmatsyah \\ STMIK Atma Luhur ; Jl. Jend. Sudirman, Kel. Selindung Pangkalpinang \\ Program Studi Sistem Informasi \\ dendi@atmaluhur.ac.id
}

\begin{abstract}
Abstrak
Perkembangan teknologi saat ini sangatlah pesat. Kemajuan disetiap bidang tidak terlepas dari teknologi sebagai faktor pendukungnya, terutama di bidang teknologi informasi. Teknologi informasi (TI) merupakan suatu bagian yang sangat penting bagi perusahaan atau organisasi dan merupakan suatu nilai investasi untuk menjadikan perusahaan atau organisasi tersebut menjadi lebih baik. Perusahaan atau organisasi menempatkan teknologi informasi sebagai suatu hal yang dapat mendukung pencapaian rencana strategis perusahaan untuk mencapai sasaran visi, misi dan tujuan perusahaan atau organisasi tersebut, Akan tetapi hal tersebut harus dimbangi dengan adanya sebuah analisis atau audit terhadap sistem informasi sehingga ancaman atau kerugian dapat dihindari ataupun dicegah. Penelitian ini bertujuan mengetahui sejauh mana pengembangan sistem Aplikasi AOK-JEK tersebut sebagai layanan publik yang telah di implementasikan pada masyarakat. AOK-JEK adalah sebuah layanan aplikasi ojek online lokal di Bangka Belitung yang di launching pada awal januari 2017. Selama ini Aplikasi AOK-JEK hanya sebatas penggunaannya saja, tanpa melihat dari segi ke optimalisasinya. Untuk mengetahui ke optimalisasian Aplikasi AOK-JEK tersebut maka digunakanlah Fremwork Cobit untuk mengetahui sejauh mana ke optimalan aplikasinya. Dengan menggunakan Fremwork Cobit dapat diketahui hasil opimalisasi pada level yang sudah efektif.
\end{abstract}

Kata kunci: Analisis, Audit Teknologi Informasi, Cobit, Aplikasi, Organisasi.

\begin{abstract}
The development of technology today is very rapid. Progress in every field can not be separated from technology as a supporting factor, especially in the field of information technology. Information technology (IT) is a very important part for the company or organization and is an investment value to make the company or organization to be better. Companies or organizations put information technology as a thing that can support the achievement of the company's strategic plan to achieve the target vision, mission and goals of the company or organization, But it must be balanced with the existence of an analysis or audit of information systems so that threats or losses can be avoided or prevented. This study aims to determine the extent to which the development of AOK-JEK Application system is a public service that has been implemented in the community. AOK-JEK is a local online ojek service application in Bangka Belitung which was launched in early january 2017. During this time AOK-JEK Application is limited to its use only, without looking in terms of to optimisasinya. To know the optimization of the AOK-JEK Application is used Cobem Fremwork to find out how far to optimize the application. By using the Cobit Fremwork can be seen the results of optimization at a level that is already effective.
\end{abstract}

Keywords: Analysis, Information Technology Audit, Cobit, Applications, Organization. 


\section{PENDAHULUAN}

erusahaan merupakan suatu organisasi yang terdiri dari manusia dengan berbagai macam karakter yang bekerja secara bersamaan sesuai dengan fungsi dan tugasnya masing-masing, akan tetapi masing-masing individual punya tujuan yang sama. Teknologi Informatika dewasa ini berkembang sangat pesat sehingga Teknologi Informasi sangat berperan dan menjadi kebutuhan manusia yang semakin kompleks, serta ketergantungannya terhadap teknologi informasi tersebut.

Perkembangan Teknologi Informasi semakin pesat seperti yang terjadi pada angkutan umum yang berbasis online. Aok-Jek adalah salah satu aplikasi ojek online yang berkembang di Provinsi Kepulauan Bangka Belitung dan Aok-jek merupakan aplikasi original karya anak Bangka Belitung itu sendiri. Dalam studi kasus ini penulis mencoba untuk mengaudit aplikasi Aok-Jek menjadi lebih sempurna seperti yang diharapkan perusahaan atau organisasi tersebut dan dimana judul jurnal "Pengembangan Aplikasi Aok-Jek Menggunakan Kerangka Kerja COBIT 4.1 Untuk Meningkatkan Pelayanan Pelanggan". Fokus permasalahan pada pengamatan ini antara lain:

1. Belum efektifnya fitur-fitur yang ada pada aplikasi Aok-Jek tersebut.

2. Perlu adanya Audit Sistem Informasi atau Penerapan Teknologi Informasi terhadap pengembangan Aplikasi Aok-Jek tersebut.

3. Perlu adanya penambahan fitur, pengembangan, update dan maintenance pada Aplikasi Aok-Jek agar lebih efektif dan efisien untuk kenggunaannya dimasa yang akan datang.

Tujuan pengamatan antara lain:

1. Mempelajari pengembangan Aplikasi Teknologi Informasi sesuai dengan standar CoBIT Framework.

2. Membuat suatu rancangan pengembangan aplikasi untuk infrastruktur yang relevan dengan kegiatan operasional sehari-hari pada Aok-Jek, yang di sesuai dengan standar CoBIT Framework.

3. Membangun tata kelola aplikasi Aok-Jek yang mampu mengimplementasi dan dapat menilai tingkat kematangan sesuai dengan standar CoBIT Framework.

4. Aplikasi ini akan menghasilkan suatu keluaran berupa tingkat kematangan tata kelola Teknologi Informasi organisasi yang digunakan oleh PT. Aok Teknologi Indonesia (Aok-Jek)

\section{1. Audit}

Audit pada dasarnya adalah proses sistematis dan obyektif dalam memperoleh dan mengevaluasi bukti-bukti tindakan ekonomi, guna memberikan pernyataan dan menilai seberapa jauh tindakan ekonomi sudah sesuai dengan kriteria yang berlaku dan mengkomunikasikan hasilnya kepada pihak yang terkait.

\subsection{Audit Sistem Informasi}

Audit Sistem Informasi (SI) atau (TI) adalah suatu proses pengumpulan dan pengevaluasian bukti untuk menentukan apakah sistem informasi dapat melindungi aset, teknologi informasi yang ada telah memelihara integritas data sehingga keduanya dapat diarahkan kepada pencapaian tujuan bisnis secara efektif dengan menggunakan sumber daya yang efisien [1]. Pada hakekatnya, audit sistem informasi sebagai audit tersendiri dan bukan bagian dari audit laporan keuangan, perlu dilakukan untuk memeriksa tingkat kematangan atau kesiapan suatu organisasi dalam melakukan pengelolaan teknologi informasi (IT governance) [2]. Tingkat kesiapan (level of maturity) dapat dilihat dari suatu tata kelola informasi, tingkat kepedulian seluruh stakeholders tentang posisi sekarang dan arah yang diinginkan di masa yang akan datang. Sehingga perencanaan Teknologi Informasi hendaknya dilakukan dengan kesungguhan

Rachmatsyah et.al (Pengembangan Aplikasi Aok-Jek Menggunakan Kerangka Kerja COBIT 4.1 Untuk 
dan keseriusan. Tata kelola teknologi informasi melakukan penspesifikasian hak keputusan dan rerangka akuntabilitas untuk mengarahkan perilaku yang diinginkan dalam penggunaan teknologi informasi [3].

\subsection{Definisi CoBIT}

CoBIT (Control Objective for Information and Related Technology) adalah suatu metodologi yang memberikan kerangka dasar dalam menciptakan sebuah Teknologi Informasi yang sesuai dengan kebutuhan organisasi dan tetap memperhatikan faktor-faktor lain yang berpengaruh [4]. Kumpulan dokumentasi best practices untuk IT governance yang dapat membantu auditor, manajemen dan pengguna untuk menjembatani gap antara resiko bisnis, kebutuhan kontrol dan permasalahan teknis.

CoBIT adalah suatu framework untuk membangun suatu IT Governance. Dengan mengacu pada framework CoBIT, suatu organisasi diharapkan mampu menerapkan IT governance dalam pencapaian tujuannya IT governance mengintegrasikan cara optimal dari proses perencanaan dan pengorganisasian, pengimplementasian, dukungan serta proses pemantauan kinerja Teknologi Informasi [5]. CoBIT memiliki fungsi antara lain:

a. Meningkatkan pendekatan/program audit.

b. Mendukung audit kerja dengan mengarahkan audit secara rinci.

c. Memberikan petunjuk dan pengarahan untuk IT governance.

d. Sebagai acuan penilaian benchmark untuk kendali Sistem Informasi atau Teknologi Informasi.

e. Meningkatkan kontrol Sistem Informasi atau Teknologi Informasi.

f. Sebagai standarisasi pendekatan atau program audit.

\subsection{Framework CoBIT}

Konsep dasar kerangka kerja CoBIT adalah penentuan kendali dalam TI berdasarkan informasi yang dibutuhkan untuk mendukung tujuan bisnis dan informasi yang dihasilkan dari gabungan penerapan proses TI dan sumber daya terkait [4]. Dalam penerapan pengelolaan TI terdapat dua jenis model kendali, yaitu model kendali bisnis (business controls model) dan model kendali TI (IT focused control model), CoBIT mencoba untuk menjembatani kesenjangan dari kedua jenis kendali tersebut. CoBIT di rancang terdiri dari 34 high level control objectives yang menggambarkan proses TI yang terdiri dari 4 domain yaitu: Plan and Organise, Acquire and Implement, Deliver and Support dan Monitor and Evaluate. Berikut kerangka kerja CoBIT yang terdiri dari 34 proses TI yang terbagi ke dalam 4 domain pengelolaan, yaitu [4]:

A. Align, Plan and Organize (APO), Mencakup masalah mengidentifikasikan cara terbaik TI untuk memberikan kontribusi yang maksimal terhadap pencapaian tujuan bisnis organisasi. Domain ini menitik beratkan pada proses perencanaan dan penyelarasan strategi TI dengan strategi organisasi. Domain PO terdiri dari 10 control objectives, yaitu:
a. POI - Define a strategic IT plan
b. PO2 - Define the information architechture
c. PO3 - Determine technological direction
d. PO4 - Define IT processes, organisation and relationships
e. PO5 - Manage the IT investment
f. PO6 - Communicate management ains and direction
g. PO7 - Manage IT human resource
h. PO8 - Manage quality
i. $\quad$ PO9 - Asses and manage IT risks
j. PO10-Manage projects 
B. Build, Acquire and Implement (BAI), domain ini menitikberatkan pada proses pemilihan, pengadaaan dan penerapan TI yang digunakan. Pelaksanaan strategi yang telah ditetapkan, harus disertai solusi-solusi TI yang sesuai dan solusi TI tersebut diadakan, diimplementasikan dan diintegrasikan ke dalam proses bisnis organisasi. Domain AI terdiri dari 7 control objectives, yaitu:
a. AII - Identify automated solutions
b. AI2 - Acquire and maintain application software
c. AI3 - Acquire and maintain technology infrastructure
d. AI4 - Enable operation and use
e. AI5 - Procure IT resources
f. AI6 - Manage changes
g. AI7 - Install and accredit solutions and changes

C. Delivery, Service and Support (DSS), domain ini menitikberatkan pada proses pelayanan TI dan dukungan teknisnya yang meliputi hal keamanan sistem, kesinambungan layanan, pelatihan dan pendidikan untuk pengguna, dan pengelolaan data yang sedang berjalan. Domain DS terdiri dari 13 control objectives, yaitu:
a. DS1 - Define and manage service levels.
b. DS2 - Manage third-party services.
c. DS3 - Manage performance and capacity.
d. DS4 - Ensure continuous service.
e. DS5 - Ensure systems security.
f. DS6 - Identify and allocate costs
g. DS7 - Educate and train users.
h. DS8 - Manage service desk and incidents.
i. DS9-Manage the configuration.
j. DS10-Manage problems.
k. DS11-Manage data.
1. DS12 - Manage the physical environment.
m. DS13-Manage operations.

D. Monitoring, Evaluation and Assess (MEA), domain ini menitikberatkan pada proses pengawasan pengelolaan TI pada organisasi seluruh kendali-kendali yang diterapkan setiap proses TI harus diawasi dan dinilai kelayakannya secara berkala. Domain ini fokus pada masalah kendali-kendali yang diterapkan dalam organisasi, pemeriksaan internal dan eksternal. Berikut proses-proses TI pada domain monitoring and evaluate:
a. ME1 - Monitor and evaluate IT performance.
b. ME2 - Monitor and evaluate internal control.
c. ME3 - Ensure regulatory compliance.
d. ME4 - Provide IT Governance.

Dengan melakukan kontrol terhadap ke 34 obyektif tersebut, organisasi dapat memperoleh keyakinan akan kelayakan tata kelola dan kontrol yang diperlukan untuk lingkungan TI. Untuk mendukung proses TI tersebut tersedia sekitar 215 tujuan kontrol yang lebih detail untuk menjamin kelengkapan dan efektifitas implementasi.

\subsection{Model Maturity}

CoBIT mempunyai model kematangan (maturity models) untuk mengontrol proses-proses TI dengan menggunakan metode penilaian (scoring) sehingga suatu organisasi dapat menilai proses-proses TI yang dimilikinya dari skala nonexistent sampai dengan optimised (dari 0 sampai 5). Dengan adanya maturity level model, maka organisasi dapat mengetahui posisi

Rachmatsyah et.al (Pengembangan Aplikasi Aok-Jek Menggunakan Kerangka Kerja COBIT 4.1 Untuk 
kematangannya saat ini, dan secara terus menerus serta berkesinambungan harus berusaha untuk meningkatkan levelnya sampai tingkat tertinggi agar aspek governance terhadap teknologi informasi dapat berjalan secara efektif.

\subsection{Perhitungan Maturity}

Pada level mengolah kuesioner, peneliti akan melakukan analisis data menggunakan software Microsoft excel. Adapun langkah-langkah untuk perhitungan Maturity Level sebagai berikut:

a. Perhitungan tiap pertanyaan Maturity Level (ML) bisa dilakukan dengan cara $(1,2)$.

$$
\begin{aligned}
I M & =\frac{\sum(\text { jumlah jawaban } x \text { maturity level })}{\text { jumlah pertanyaan } x \text { jumlah responden }} \\
& =\frac{{ }_{x}^{-} P_{1}+{ }_{x}^{-} P_{2}+{ }_{x}^{-} P_{3}+{ }_{x}^{-} P_{, n}}{\sum(P n)}
\end{aligned}
$$

b. Menentukan nilai normalisasii tiap tingkat kematangan dengan cara membagi rata-rata tiap Maturity Level dengan total tingkat Meturity Level.

c. Menghitung nilai kontribusi dengan cara mengalikan nilai normalisasi dengan masingmasing tingkat Maturity.

d. Menjumlahkan semua nilai kontribusi yang didapat.

$$
\text { Total Nilai Kontribusi }=\text { Tingkat Kematangan }(\text { Maturity Level Process })
$$

Dari rumus yang didapat, maka penilaian bisa dilakukan seperti pada Tabel 1 [4].

Tabel 1. Penilaian Skala Maturity Model

\begin{tabular}{|c|l|}
\hline O- No Existent & $\begin{array}{l}\text { Perusahaan sama sekali tidak perduli terhadap pentingnya teknologi } \\
\text { informasi untuk dikelola secara baik oleh manajemen. }\end{array}$ \\
\hline 1 Initial & $\begin{array}{l}\text { Perusahaan secara reaktif melakukan penerapan dan implementasi } \\
\text { teknologi informasi sesuai dengan kebutuhan-kebutuhan mendadak yang } \\
\text { ada, tanpa didahului dengan perencanaan sebelumnya }\end{array}$ \\
\hline 2- Repeatable & $\begin{array}{l}\text { Perusahaan telah memiliki pola yang berulangkali dilakukan dalam } \\
\text { melakukan manajemen aktivitas terkait dengan tata kelola teknologi } \\
\text { informasi, namun keberadaannya belum terdefinisi secara baik dan formal } \\
\text { sehingga masih terjadi ketidakkonsistenan }\end{array}$ \\
\hline 3 Define & $\begin{array}{l}\text { Perusahaan telah memiliki prosedur baku formal dan tertulis yang telah } \\
\text { disosialisasikan ke segenap jajaran manajemen dan karyawan untuk } \\
\text { dipatuhi dan dikerjakan dalam aktivitas sehari-hari. }\end{array}$ \\
\hline 4 Manage & $\begin{array}{l}\text { Perusahaan telah memiliki sejumlah indikator atau ukuran kuantitatif yang } \\
\text { dijadikan sebagai sasaran maupun obyektif kinerja setiap penerapan } \\
\text { aplikasi teknologi informasi yang ada. }\end{array}$ \\
\hline Optimised & $\begin{array}{l}\text { Perusahaan telah mengimplementasikan tata kelola teknologi informasi } \\
\text { yang mengacu pada "best practice" }\end{array}$ \\
\hline
\end{tabular}

Tingkat kemampuan proses 0 tidak memiliki atribut. Level 0 ini mencerminkan tidak akan di implementasikan proses atau proses yang gagal untuk setidaknya mencapai sebagian hasil-

Rachmatsyah et.al (Pengembangan Aplikasi Aok-Jek Menggunakan Kerangka Kerja COBIT 4.1 Untuk Meningkatkan Pelayanan Pelanggan) 
hasilnya [6].

\section{METODE PENELITIAN}

Teknik pengumpulan data ini adalah dengan metode wawancara dan kuisioner [7]. Teknik ini dilakukan dengan cara mengajukan pertanyaan ke narasumber dan mengajukan kuisioner ke setiap driver yang mengetahui tentang aplikasi. Teknik ini untuk mendapatkan informasi yang digunakan untuk audit pengembangan aplikasi. Wawancara dilakukan di Kantor Aok-Jek dengan 3 narasumber sebagai pendiri aplikasi dan di pangkalan driver Aok-Jek untuk kuisioner.

\subsection{Metode Pengumpulan Data}

Metode pengumpulan data pada penelitian ini menggunakan metode Interview atau wawancara. Metode dimana pengumpulan data dengan cara wawancara atau bertanya langsung kepada pihak yang mendirikan perusahaan, dan pada penelitian ini juga menggunakan metode kuisioner dengan driver yang bersangkutan sesuai dengan domain dan control objective yang digunakan untuk audit pengembangan aplikasi Aok-Jek. Penulis memberi daftar pertanyaan kepada tiga narasumber pendiri Perusahaan Aok-Jek dan kuisioner kepada masing-masing driver Aok-Jek untuk memperoleh data dan informasi yang diperlukan.

\subsection{Metode Analisis Data}

Metode analisis data pada penelitian ini dilakukan dengan beberapa tahap, yaitu:

a. Penentuan Domain

Pada tahap ini domain yang akan dievaluasi berdasarkan kebutuhan layanan Teknologi Informasi dari fakultas dengan mengadopsi standar domain yang terdapat dalam kerangka kerja CoBIT yaitu: Plan and Organise (PO), Acquireand Implement (AI), Deliver and Support (DS) dan Monitor and Evaluate (ME).

b. Penentuan Proses Kontrol

Pada tahap ini dibuat daftar skala prioritas terhadap proses kontrol yang terdapat dalam masing-masing domain yang telah ditentukan pada tahap sebelumnya. Untuk mendapatkan skala prioritas proses kontrol dibuatlah kuisioner yang disebarkan kepada narasumber.

c. Penentuan Indikator Kerja

Indikator kinerja mendefinisikan bagaimana proses fungsi Teknologi Informasi dapat dilaksanakan dengan baik untuk mencapai suatu tujuan. Penentuan indikator berdasarkan control objective dari masing-masing proses kontrol dalam kerangka kerja CoBIT.

d. Pada penelitian ini menggunakan 11 control objective dari 4 domain antara lain:

1. Domain Plan and Organise (PO)

a. PO1 Pendefinisian Rencana Strategis Teknologi Informasi

b. PO4 Pendefinisian Proses Teknologi Informasi, Organisasi dan keterhubungannya

c. PO7 Manajemen Sumber Daya Manusia (SDM)

2. Domain Acquire and Implement (AI)

a. AI1 Mengidentifikasi Solusi Otomatis

b. AI3 Pemeliharaan Infrastruktur Teknologi Informasi

c. AI6 Mengelola Perubahan

3. Domain Deliver and Support (DS)

a. DS1 Menetapkan dan Mengelola Tingkat Layanan 


\section{b. DS11 Mengelola Data}

4. Domain Monitor and Evaluate (ME)

a. ME1 Mengawasi dan Mengevaluasi Kinerja Teknologi Informasi

b. ME2 Mengawasi dan Mengevauasi Kontrol Internal

c. ME4 Menyediakan Tata Kelola Teknologi Informasi

\section{HASIL DAN PEMBAHASAN}

Pada tahap penelitian ini agar diperoleh data yang valid, maka data diperoleh melalui beberapa bagian yang diantaranya, wawancara dan kuesioner. Hasilnya akan direpresentasikan kemudian.

\subsection{Wawancara}

Berdasarkan dari wawancara telah disimpulkan hasilnya pada Tabel 2.

Tabel 2. Hasil Wawancara

\begin{tabular}{|c|c|c|}
\hline No. & Pertanyaan & Jawaban \\
\hline 1 & Kapan terbentuknya Aok-jek? & $\begin{array}{l}\text { Terbentuknya pada bulan November } 2016 \\
\text { lalu. }\end{array}$ \\
\hline 2 & $\begin{array}{l}\text { Dari mana ide ini berasal dan apa yg } \\
\text { melatar belakangi aplikasi tersebut? }\end{array}$ & $\begin{array}{l}\text { Saya (Vinsensius) sendiri yang memberi ide, } \\
\text { dan yang melatar belakanginya adalah } \\
\text { teman-teman aokjek pertama kali }\end{array}$ \\
\hline 3 & $\begin{array}{l}\text { Berapa lama waktu yang di butuhkan } \\
\text { dalam pembuatan aplikasi ini? }\end{array}$ & $\begin{array}{l}\text { Kurang lebih } 2 \text { bulan dari } \\
\text { perencanaan,desain dan } \\
\text { peluncuran/perkenalan aplikasi ini }\end{array}$ \\
\hline 4 & $\begin{array}{l}\text { Bahasa pemrograman apa dalam } \\
\text { pembuatan aplikasi ini? }\end{array}$ & Php, html, java , dan GIS \\
\hline 5 & $\begin{array}{l}\text { Berapa kali peng-Update tan Aplikasi } \\
\text { tersebut, SS update pertama dan alasan } \\
\text { pengupdatetan sampai skrg? }\end{array}$ & $\begin{array}{l}\text { Sampai saat ini aokjek sudah di perbarui } \\
\text { sebanyak } 20 \text { kali agar aplikasi ini lebih } \\
\text { efektif dan nyaman serta mudah untuk } \\
\text { digunakan. }\end{array}$ \\
\hline 6 & $\begin{array}{l}\text { OS Smartphone apa saja yg support } \\
\text { untuk aplikasi ini? }\end{array}$ & Untuk saat ini hanya pada Android saja. \\
\hline 7 & Data base apa yg anda gunakan? & $\begin{array}{l}\text { Database yang kami gunakan adalah } \\
\text { Firebase }\end{array}$ \\
\hline 8 & $\begin{array}{l}\text { Metode apa yang di gunakan dalam } \\
\text { pembuatan aplikasi ini? }\end{array}$ & $\begin{array}{l}\text { Metode yang saya gunakan adalah Metode } \\
\text { Secrum. }\end{array}$ \\
\hline 9 & $\begin{array}{l}\text { Server Apa yg anda gunakan dan apa } \\
\text { alasannya? }\end{array}$ & $\begin{array}{l}\text { Server kita sekarang berada di singapore, } \\
\text { karena akses nya lebih cepat }\end{array}$ \\
\hline 10 & $\begin{array}{l}\text { Apa Masalah yg sering terjadi pada } \\
\text { Driver? }\end{array}$ & $\begin{array}{l}\text { Navigasi nya tidak tepat karena aplikasi GPS } \\
\text { pada costumer tak terupdate dengan baik }\end{array}$ \\
\hline
\end{tabular}

Berdasarkan wawancara yang kami lakukan terhadap pendiri Aok-Jek dapat disimpulkan bahwa Aplikasi ini mulai di perkenalkan pada bulan November 2016 dengan menggunakan Aplikasi WhatsApp dan website, kemudian berangsur-angsur mulai membuat Aplikasi perdana Aok-Jek dengan 4 fitur menu. Awalnya ide tersebut berasal dari seorang Sales Otomotif yang berniat mempermudah kebutuhan masyarakat, terutama di bidang Transportasi. Mulanya Aplikasi ini menggunakan server lokal tetapi terdapat banyak kendala terutama kecepatan akses

Rachmatsyah et.al (Pengembangan Aplikasi Aok-Jek Menggunakan Kerangka Kerja COBIT 4.1 Untuk 
yang lama. Kemudian pendiri memutuskan untuk menggunakan server dari luar negeri yaitu Singapore dan database nya mereka menggunakan Firebase. Dalam pembuatan aplikasi ini programmer memilih menggunakan metode Scrum yang menurutnya sangat efektif untuk Aplikasi ini. Programmer juga melakukan Revisi atau pengupdatean dan maintenance secara berkala sesuai dengan kebutuhan masyarakat saat ini seiring perkembangan zaman. Untuk saat ini operasi sistem smartphone yang mendukung aplikasi ini adalah Android di karenakan OS Android merupakan OS yang open source. Bahasa pemrograman yang digunakan programmer itupun adalah PHP, Java, HTML, dan GIS tidak menutup kemungkinan programmer akan menggunakan bahasa pemrograman lainnya sesuai dengan kebutuhan.Terkadang terdapat pada kendala yang dihadapi para programmer terhadap driver berupa Navigasi yang kurang tepat. Dalam hal ini programmer akan terus memperbaharui aplikasi ini dengan sangat baik demi kenyamanan konsumen, driver dan pemilik perusahaan itu sendiri.

\subsection{Kuesioner}

Kriteria Penilaian Tingkat Kepuasan Berikut ini terlampir pada Tabel 3.

Tabel 3. Penilaian Tingkat Kepuasan

\begin{tabular}{|l|c|}
\hline \multicolumn{1}{|c|}{ Keterangan } & Bobot \\
\hline Sangat Setuju (SS) & 4 \\
\hline Setuju (S) & 3 \\
\hline Tidak Setuju (TS) & 2 \\
\hline Sangat Tidak Setuju (STS) & 1 \\
\hline
\end{tabular}

Penggolongan kategori tiap indikator dihitung berdasarkan nilai yang diperoleh dari hasil kuesioner dengan cara mengalihkan besar bobot (nilai) pada kategori tertentu yang telah ditetapkan dengan jumlah responden yang menjawab masing-masing kategori tersebut. Berdasarkan dengan jumlah dari 50 responden, maka dapat ditentukan bobot penilaian dengan menggunakan jarak yang dapat dihitung melalui nilai tertinggi dan nilai terendah $(4,5,6,7)$.

$$
\begin{aligned}
& \text { Jarak }=\text { Jarak Tertinggi }- \text { Jarak Terendah } \\
& \text { Nilai Tertinggi }=\text { Total Responden } \times \text { Bobot Terbesar } \\
& \text { Nilai Terendah }=\text { Total Responden } \times \text { Bobot Terkecil } \\
& \text { Interval }=\frac{\text { Jarak }}{\text { Banyaknya Kelas }}
\end{aligned}
$$

Adapun tabel interval dan penilaian yang menjadi tolak ukur bisa dilihat pada Tabel 4.

Tabel 4. Interval dan Penilaian

\begin{tabular}{|l|l|}
\hline Interval & \multicolumn{1}{c|}{ Penilaian } \\
\hline $0-26$ & Sangat Tidak Puas \\
\hline $27-51$ & Cukup Puas \\
\hline $52-76$ & Puas \\
\hline $78-104$ & Sangat Puas \\
\hline
\end{tabular}

Sedangkan untuk hasil dari indikator variabel kegunaan (usability) bisa Anda lihat pada Tabel 5.

Tabel 5. Variabel Kegunaan (Usability) 
Jatisi

ISSN 2407-4322

Vol. 5, No. 1, September 2018, Hal. 24-35

\begin{tabular}{|c|c|c|c|c|}
\hline No & Indikator Variabel & SKOR & PERSENTASE & KETERANGAN \\
\hline 1 & $\begin{array}{l}\text { Aplikasi sangat } \\
\text { mudah dioperasikan. }\end{array}$ & 83 & $80 \%$ & Sangat Puas \\
\hline 2 & $\begin{array}{lrr}\text { Interaksi } & \text { yang } & \text { terjadi } \\
\text { antara } & \text { saya } & \text { dan } \\
\text { Apliksi } & \text { sangat } \\
\text { dipahami } & \text { dan } \\
\text { mengerti. } & \\
\end{array}$ & 88 & $85 \%$ & Sangat Puas \\
\hline 3 & $\begin{array}{lr}\text { Aplikasi } & \text { sangat } \\
\text { mudah } & \text { untuk } \\
\text { dinavigasikan. } & \\
\end{array}$ & 88 & $85 \%$ & Sangat Puas \\
\hline 4 & $\begin{array}{l}\text { Apikasi sangat mudah } \\
\text { untuk dinavigasikan. }\end{array}$ & 89 & $85 \%$ & Sangat Puas \\
\hline 5 & $\begin{array}{lr}\text { Aplikasi } & \text { memiliki } \\
\text { penampilan } & \text { yang } \\
\text { cuku atraktif. } & \\
\end{array}$ & 89 & $85 \%$ & Sangat Puas \\
\hline 6 & $\begin{array}{l}\text { Desainnya sangat } \\
\text { sesuai dengan jenis } \\
\text { situs itu sendiri. }\end{array}$ & 87 & $83 \%$ & Sangat Puas \\
\hline 7 & $\begin{array}{l}\text { Penggunaan tombol } \\
\text { Exit, Help, Rate. }\end{array}$ & 84 & $81 \%$ & Sangat Puas \\
\hline 8 & $\begin{array}{ll}\text { Aplikasi } & \text { ini } \\
\text { memberikan } & \\
\text { pengalaman } & \text { positif } \\
\text { bagi saya. } & \\
\end{array}$ & 87 & $83 \%$ & Sangat puas \\
\hline
\end{tabular}

Sedangkan untuk hasil dari indikator variabel kualitas informasi (Quality Information) bisa Anda lihat pada Tabel 6.

Tabel 6. Variabel Kualitas Informasi (Quality Information)

\begin{tabular}{|c|c|c|c|c|}
\hline No & Indikator Variabel & SKOR & PERSENTASE & KETERANGAN \\
\hline 1 & $\begin{array}{lr}\text { Kompleksitas yang } \\
\text { dimiliki } & \text { oleh } \\
\text { Apliksai } & \text { tergolong } \\
\text { lengkap. } & \\
\end{array}$ & 81 & $78 \%$ & Sangat Puas \\
\hline 2 & $\begin{array}{ll}\begin{array}{l}\text { Menyediakan } \\
\text { informasi } \\
\text { akurat. }\end{array} & \\
\end{array}$ & 86 & $82 \%$ & Sangat Puas \\
\hline 3 & $\begin{array}{l}\text { Memberikan } \\
\text { informasi yang dapat } \\
\text { dipercaya. }\end{array}$ & 88 & $85 \%$ & Sangat Puas \\
\hline 4 & $\begin{array}{l}\text { Menyediakan } \\
\text { informasi yangtepat } \\
\text { waktu atau update. }\end{array}$ & 89 & $85 \%$ & Sangat Puas \\
\hline
\end{tabular}




\begin{tabular}{|c|c|c|c|c|}
\hline 5 & $\begin{array}{ll}\text { Menyediakan } & \\
\text { informasi } & \text { yang } \\
\text { relavan. } & \\
\end{array}$ & 85 & $85 \%$ & Sangat Puas \\
\hline 6 & $\begin{array}{l}\text { Penyampaian akan } \\
\text { pemahaman } \\
\text { informasi } \\
\text { mudah. }\end{array}$ & 87 & $82 \%$ & Sangat Puas \\
\hline 7 & $\begin{array}{l}\text { Memberikan } \\
\text { informasi yang detail } \\
\text { pada tingkat yang } \\
\text { tepat. }\end{array}$ & 83 & $83 \%$ & Sangat Puas \\
\hline 8 & $\begin{array}{l}\text { Menyediakan } \\
\text { informasi dalam } \\
\text { format yang sesuai. }\end{array}$ & 82 & $89 \%$ & Sangat puas \\
\hline 9 & $\begin{array}{lr}\text { Bahasa dalam } \\
\text { informasi yang } \\
\text { disampaikan tidak } \\
\text { sesuai dengan kaidah } \\
\text { bahasa indonesia } \\
\text { dengan ejaan yang } \\
\text { disempurnakan. }\end{array}$ & 82 & $79 \%$ & Sangat puas \\
\hline 10 & $\begin{array}{l}\text { Penggunaan bahasa } \\
\text { asing dalam aplikasi } \\
\text { sesuai dengan aturan } \\
\text { yang berlaku } \\
\text { kosakata variabel dan } \\
\text { sebagainya. }\end{array}$ & 84 & $82 \%$ & Sangat puas \\
\hline 11 & $\begin{array}{l}\text { Kerahasian informasi } \\
\text { tetap terjaga. }\end{array}$ & 81 & $81 \%$ & Sangat puas \\
\hline
\end{tabular}

Sedangkan untuk hasil dari indikator variabel kualitas interaksi (Interaction Quality) bisa Anda lihat pada Tabel 7 .

Tabel 7. Variabel Kualitas Interaksi

\begin{tabular}{|c|l|c|c|c|}
\hline No & Indikator Variabel & SKOR & PERSENTASE & KETERANGAN \\
\hline 1 & $\begin{array}{l}\text { Memiliki reputasi } \\
\text { kelompok. }\end{array}$ & 81 & $78 \%$ & Sangat Puas \\
\hline 2 & $\begin{array}{l}\text { Rasanya aman untuk } \\
\text { menyelesaikan setiap } \\
\text { transaksi atau } \\
\text { sejenisnya didalam } \\
\text { Aplikasi. }\end{array}$ & 86 & $82 \%$ & Sangat Puas \\
\hline 3 & $\begin{array}{l}\text { Saya merasa aman } \\
\text { dengan informasi } \\
\text { pribadi yang ada di } \\
\text { Aplikasi. }\end{array}$ & 88 & $85 \%$ & Sangat Puas \\
\hline
\end{tabular}


Jatisi

ISSN 2407-4322

Vol. 5, No. 1, September 2018, Hal. 24-35

\begin{tabular}{|c|l|c|c|c|}
\hline 4 & $\begin{array}{l}\text { Menimbulkan rasa } \\
\text { personalisasi } \\
\text { terhadap Aplikasi. }\end{array}$ & 89 & $85 \%$ & Sangat Puas \\
\hline 5 & $\begin{array}{l}\text { Menyampiakan rasa } \\
\text { komunitas. }\end{array}$ & 85 & $85 \%$ & Sangat Puas \\
\hline 6 & $\begin{array}{l}\text { Meudahkan } \\
\text { berkomunikasi antar } \\
\text { organisasi yang ada. }\end{array}$ & 87 & $82 \%$ & Sangat Puas \\
\hline 7 & $\begin{array}{l}\text { Akses Aplikasi } \\
\text { cepat. }\end{array}$ & 83 & $83 \%$ & Sangat Puas \\
\hline 8 & $\begin{array}{l}\text { Isi dari aplikasi } \\
\text { mudah dipahami. }\end{array}$ & 82 & $89 \%$ & Sangat Puas \\
\hline 9 & $\begin{array}{l}\text { Log out otomatis dari } \\
\text { Aplikasi. }\end{array}$ & 88 & $85 \%$ & Sangat Puas \\
\hline
\end{tabular}

\section{KESIMPULAN}

Bedasarkan analisis dan uraian dari pembahasan bab sebelumnya dapat disimpulkan bahwa untuk analisis pengembangan aplikasi Aok-Jek terhadap driver atau mitra dapat dikatakan aplikasi ini sudah efektif walaupun ada beberapa hal yang diangga masih menjadi trouble untuk aplikasi itu sendiri. Dengan adanya audit teknologi informasi dengan kerangka kerja CoBIT untuk analisis pengembangan aplikasi Aok-Jek dapat membuat programer lebih efektif dalam pengembangan aplikasi dari beberapa sumber riset.

\section{SARAN}

Beberapa saran yang dapat disampaikan pada Penelitian ini adalah sebagai berikut:

1. Analisis ini dapat dikembangkan sampai langkah implementasi solusi dan lebih terperinci mengenai pendefinisian dari bab-bab hasil pembahasan sebelumnya.

2. Tingkatkan lagi penyelesaian trouble-troubble yang terjadi pada driver baik secara makruh maupun seara garis besar.

3. Adakan perencanaan kegiatan silahtuhrahmi antar driver atau mitra karena dari hasil kuisoner masih kurang rasa komunitas antar driver atau mitra

\section{DAFTAR PUSTAKA}

[1] Weber, Ron. 1988, EDP Auditing-Conceptual Foundations and Practice. Mc Graw-Hill United States.

[2] Gondodiyoto, Sanyoto. 2007, Audit Sistem Informasi + Pendekatan CobIT, Mitra Wacana Media. Jakarta.

Rachmatsyah et.al (Pengembangan Aplikasi Aok-Jek Menggunakan Kerangka Kerja COBIT 4.1 Untuk Meningkatkan Pelayanan Pelanggan) 
[3] Ricoida, Desy Iba., 2015, Tingkat Kematangan Teknologi Informasi Menggunakan Framework COBIT pada Layanan Teknologi Informasi (Studi Kasus: STIE MDP), Jatisi_Vol_2_No_1_September 2015, ISSN: 2407-4322.

[4] Swastika, I Putu Agus, I Gusti Lanang Agung Raditya Putra. 2016, Audit Sistem Informasi dan Tata Kelola Teknologi Informasi, Andi, Yogyakarta.

[5] IT Governence Institute. 2007, COBIT ver 4.1: Framework, Contol Objectives, Management Guidelines, Maturity Models. Rolling Meadow.

[6] Andry, Johanes Fernandes. 2016, Process Capability Model Based on COBIT 5 Assessments (Case Study), Jatisi_Vol_3_No_1 September 2016, ISSN ONLINE : 25032933.

[7] Suryani, Hendriyadi. 2016, Metode Riset Kuantitatif: Teori dan Aplikasi pada Penelitian Bidang Manajemen dan Ekonomi Islam, Prenadamedia Group, Jakarta. 